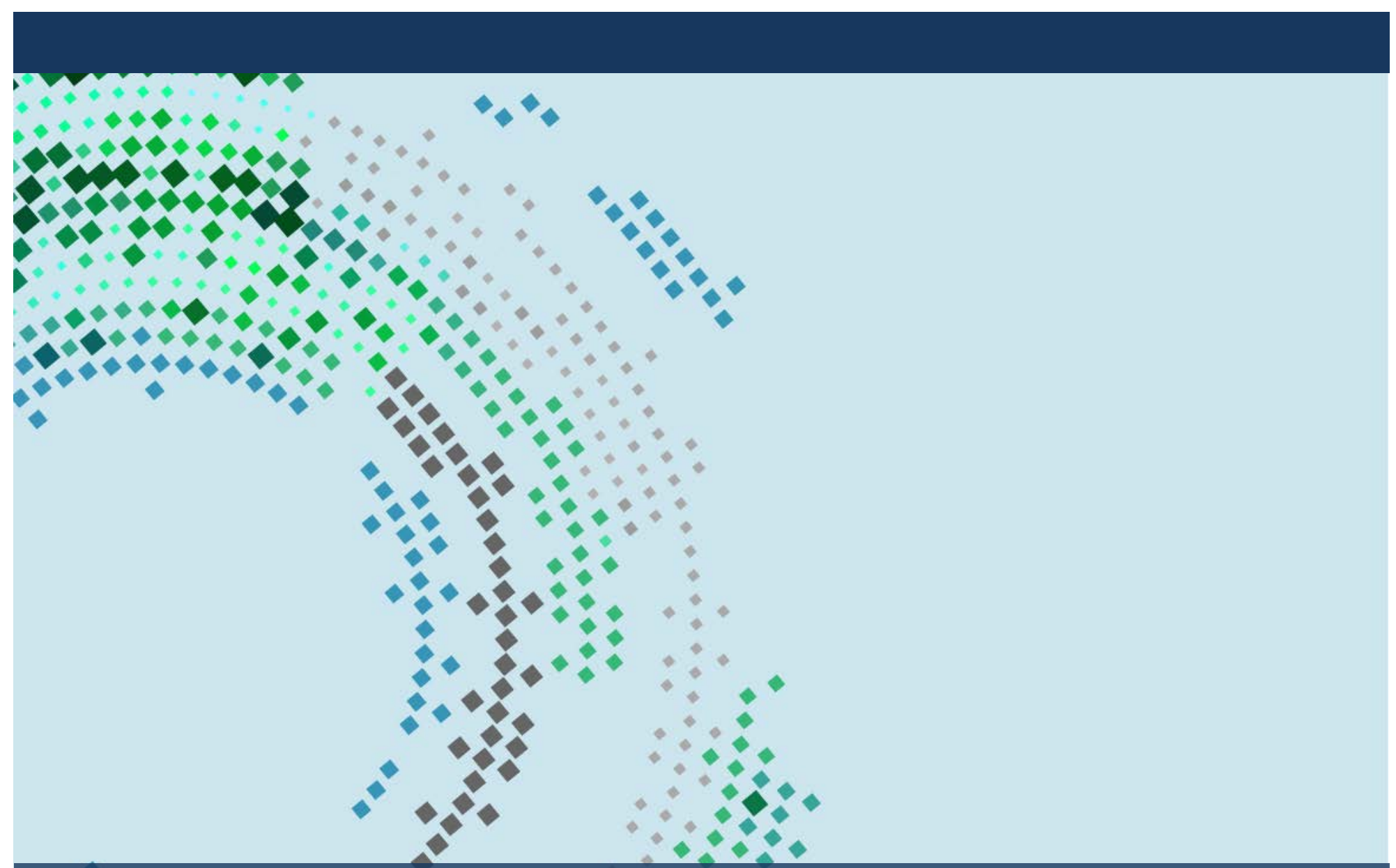

\title{
The Role of Smart Grids in Integrating Renewable Energy
}

ISGAN Synthesis Report

Annex 4, Task 3.2

Bethany Speer and Mackay Miller, National Renewable Energy Laboratory, United States

Walter Schaffer, Salzburg Netz GmbH, Austria

Leyla Gueran and Albrecht Reuter, Fichtner IT Consulting AG, Austria

Bonnie Jang, Korea Smart Grid Institute, Korea

Karin Widegren, Swedish Energy Markets Inspectorate, Sweden 


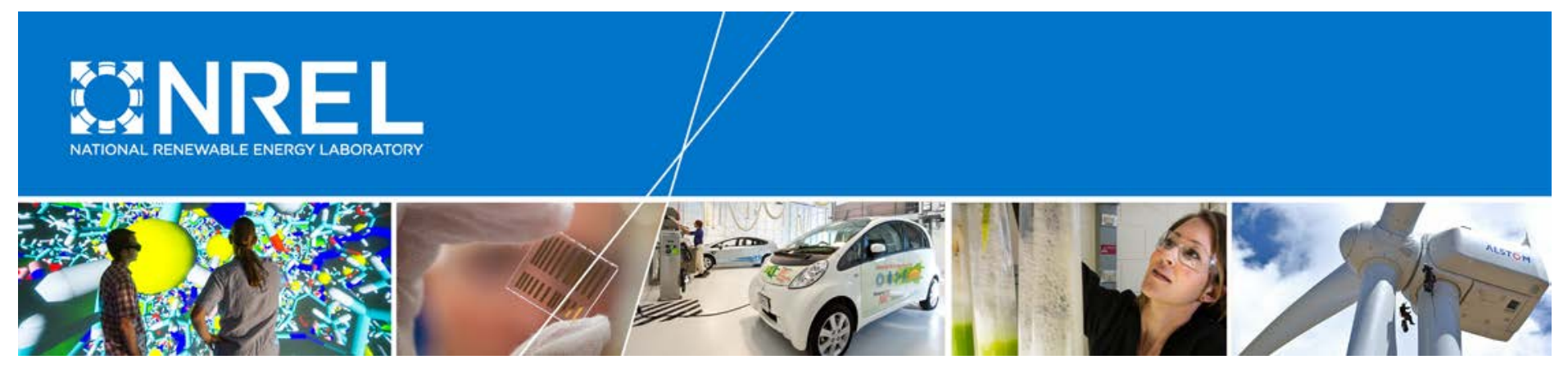

\section{The Role of Smart Grid in Integrating Renewable Energy}

Bethany Speer and Mackay Miller National Renewable Energy Laboratory

Walter Shaffer

Salzburg Netz GmbH

Leyla Gueran and Albrecht Reuter Fichtner IT Consulting AG

Bonnie Jang

Korea Smart Grid Institute

Karin Widegren

Swedish Energy Markets Inspectorate

NREL is a national laboratory of the U.S. Department of Energy Office of Energy Efficiency \& Renewable Energy

Operated by the Alliance for Sustainable Energy, LLC

This report is available at no cost from the National Renewable Energy Laboratory (NREL) at www.nrel.gov/publications.

Technical Report

NREL/TP-6A20-63919

May 2015

Contract No. DE-AC36-08GO28308 


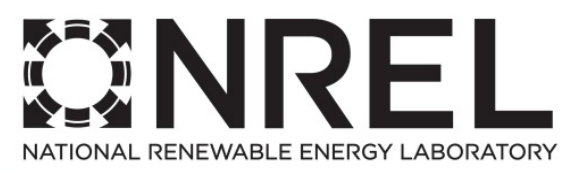

\section{The Role of Smart Grid in Integrating Renewable Energy}

Bethany Speer and Mackay Miller National Renewable Energy Laboratory

Walter Shaffer

Salzburg AG

Leyla Gueran and Albrecht Reuter Fichtner IT Consulting AG

Bonnie Jang

Korea Smart Grid Institute

Karin Widegren

Swedish Energy Markets Inspectorate

Prepared under Task No. WFH1.2143

NREL is a national laboratory of the U.S. Department of Energy Office of Energy Efficiency \& Renewable Energy Operated by the Alliance for Sustainable Energy, LLC

This report is available at no cost from the National Renewable Energy Laboratory (NREL) at www.nrel.gov/publications.

National Renewable Energy Laboratory 15013 Denver West Parkway Golden, CO 80401

303-275-3000 • www.nrel.gov
Technical Report

NREL/TP-6A20-63919

May 2015

Contract No. DE-AC36-08G028308 


\title{
NOTICE
}

This report was prepared as an account of work sponsored by an agency of the United States government. Neither the United States government nor any agency thereof, nor any of their employees, makes any warranty, express or implied, or assumes any legal liability or responsibility for the accuracy, completeness, or usefulness of any information, apparatus, product, or process disclosed, or represents that its use would not infringe privately owned rights. Reference herein to any specific commercial product, process, or service by trade name, trademark, manufacturer, or otherwise does not necessarily constitute or imply its endorsement, recommendation, or favoring by the United States government or any agency thereof. The views and opinions of authors expressed herein do not necessarily state or reflect those of the United States government or any agency thereof.

This report is available at no cost from the National Renewable Energy Laboratory (NREL) at www.nrel.gov/publications.

Available electronically at SciTech Connect http:/www.osti.gov/scitech

Available for a processing fee to U.S. Department of Energy and its contractors, in paper, from:

\author{
U.S. Department of Energy \\ Office of Scientific and Technical Information \\ P.O. Box 62 \\ Oak Ridge, TN 37831-0062 \\ OSTI http://www.osti.gov \\ Phone: 865.576.8401 \\ Fax: 865.576.5728 \\ Email: reports@osti.gov
}

Available for sale to the public, in paper, from:

\author{
U.S. Department of Commerce \\ National Technical Information Service \\ 5301 Shawnee Road \\ Alexandra, VA 22312 \\ NTIS http://www.ntis.gov \\ Phone: 800.553 .6847 or 703.605 .6000 \\ Fax: 703.605.6900 \\ Email: orders@ntis.gov
}




\section{Acknowledgements}

The authors appreciate the valuable contributions and reviews from ISGAN Annex 4 members, including recommendations from Ontario (Canada) Ministry of Energy as well as inputs from the additional country participants noted as co-authors. Also, thanks go to Karin Haas, Jeffrey Logan, and Jaquelin Cochran of NREL for their valuable recommendations.

\section{About This Report}

This report was prepared for the International Smart Grid Action Network (ISGAN), which periodically publishes briefs and discussion papers on key topics of smart grid development globally. The topic of this report was selected by a multilateral group of national experts participating in ISGAN Annex 4, a working group that aims to produce synthesis insights for decision makers. This report is an update of a 2012 ISGAN Annex 4 report entitled "Smart Grid Contributions to Variable Renewable Resource Integration." That report and other past publications of ISGAN Annexes can be found at www.iea-isgan.org and at Www.cleanenergysolutions.org.

ISGAN is an initiative of the Clean Energy Ministerial (CEM). It is formally organized as the Implementing Agreement for a Co-operative Programme on Smart Grids (ISGAN), operating under a framework of the International Energy Agency (IEA). The views, findings and opinions expressed herein do not necessarily state or reflect those of any of ISGAN's participants, any of their sponsoring governments or organizations, the CEM, the IEA Secretariat, or any of the IEA's member countries. No warranty is expressed or implied, no legal liability or responsibility is assumed for the accuracy, completeness, or usefulness of any information, apparatus, product, or process disclosed, and no representation is made that its use would not infringe privately owned rights. Reference herein to any specific commercial product, process, or service by trade name, trademark, manufacturer, or otherwise does not necessarily constitute or imply its endorsement, recommendation, or favoring. 


\section{Preface}

Flexible, strong, and smart grids play a crucial role in the integration of variable renewable energy (RE). As high levels of variable RE penetration become increasingly common across power systems, attention to grid operations and planning becomes more important. Smart grid technologies offer new options for integrating variable RE, yet technology is not the only important area of focus - innovative policy, regulation, and business models are needed to incentivize and implement next-generation grid architectures.

This discussion paper explores the intersection of smart grid technology, policy, and regulation from a non-technical point of view, focusing on some specific questions relevant for decision makers:

- What are the challenges of integrating variable RE into power grids?

- What types of smart grid solutions are emerging to integrate variable RE?

- What are good examples from around the world of smart grids aiding in the integration of variable RE?

- What types of policy and regulatory approaches are emerging to support smart grid solutions in relation to RE?

Based on emerging case studies from around the world, this discussion paper concludes that smart grids offer solutions to various challenges associated with variable RE, including providing additional flexibility, unlocking demand side participation, and deferring more costly grid upgrades. 


\section{Table of Contents}

1 Background and Current Issues ........................................................................................... 1

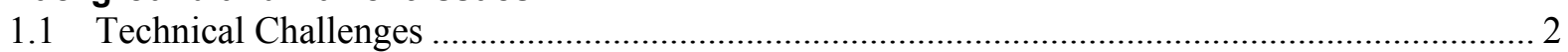

1.2 Economic, Policy, and Regulatory Challenges ................................................................ 3

2 International Case Studies: Who is Active in This Area? ...................................................... 5

2.1 Sweden: Gotland Wind Farm and Dynamic Line Rating....................................................... 5

2.2 Korea: Gapa Island Smart Grid Energy Self-Sufficiency Model .................................................. 6

2.3 Austria: Smart Grid Pilots in the Salzburg Region ....................................................... 7

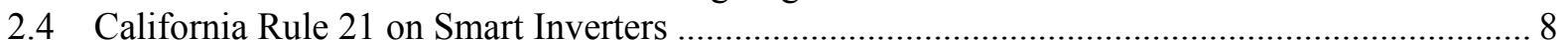

2.5 Ontario, Canada: "SmartMap" Distribution System Geographic Analysis Tool ........................ 8

3 Conclusion: Trends to Watch in 2015 and Beyond.............................................................. 10 


\section{Background and Current Issues}

Before exploring how strong, flexible, and smart grids are supporting variable RE integration around the world, we first examine the nature of variable RE grid integration challenges that have arisen recently. Two distinct categories of challenges can be identified and are the focus of this report:

1. Technical Challenges: Ensuring power system reliability as uncertainty and variability increase.

2. Economic, Policy, and Regulatory Challenges: Effectively managing the cost of RE integration and the grid investments that support it, designing policies to harness maximum value from RE, and ensuring that appropriate incentives are in place to encourage appropriate grid investments.

\section{What is a Smart Grid?}

Smart Grid is a concept and vision that captures a range of advanced information, sensing, communications, control, and energy technologies. Taken together, these result in an electric power system that can intelligently integrate the actions of all connected users-from power generators to electricity consumers to those that both produce and consume electricity ("prosumers")- to efficiently deliver sustainable, economic, and secure electricity supplies.

Source: Definition adapted from the European Technology Platform Smart Grid (ETPSG).

The following sections briefly summarize emerging challenges and solutions in both of these areas and also explore a selection of the leading solutions that can help address these challenges. While exploring all available solutions is beyond the scope of this brief report, the broader body of research by ISGAN and its national research partners helps to illuminate these areas.

Both of the above challenge areas are amplified by the growing democratization of energy supply. Specifically, cost reductions, policy innovations, and changing customer preferences are driving greater participation and investment in variable RE and power system operation by all types of end users. Consumers increasingly have the ability and the motivation to deploy distributed generation behind the meter. This is a distinct change from traditional power system organization, where large-scale centralized generators were the dominant form of supply. Enabling consumers to participate more actively in energy supply and demand can support the flexible operation of the grid and thus variable RE integration. Greater distributed generation can also, however, contribute to many of the technical and economic challenges listed below, while significantly altering the traditional utility-customer relationship.

Inflexible, rigid grids will be less able to extract maximum value from RE investments and may struggle to accommodate higher levels of variable RE. This struggle raises the likelihood of lost economic potential due to curtailed generation, challenges with maintaining a stable grid, and lost opportunities in terms of meeting environmental, climate, economic development, and energy access goals.

The interventions outlined here can help provide a framework for exploring the emerging challenges and solutions of RE integration. 


\subsection{Technical Challenges}

Two dominant technical challenges can be identified with a higher penetration of RE generation: 1) managing variability and uncertainty during the continuous balancing of the system, and 2) balancing supply and demand during generation scarcity and surplus situations.

Managing variability and uncertainty during the continuous balancing of the system

Variable RE sources are both more

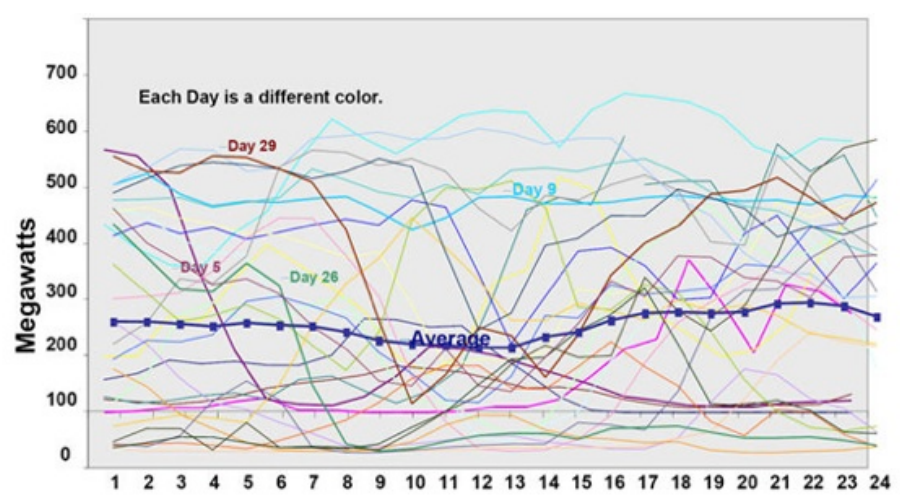

Figure 1. Tehachapi wind farm output, 30 successive days

(Source: California ISO 2007) uncertain and more variable than conventional generators. Wind farms provide a useful illustration of uncertainty: while the farm may reliably produce power for $40 \%$ of the hours in a year, it is not easy to predict far in advance when generation will occur. Figure 1 illustrates hourly output from a single wind farm on 30 successive days. ${ }^{1}$

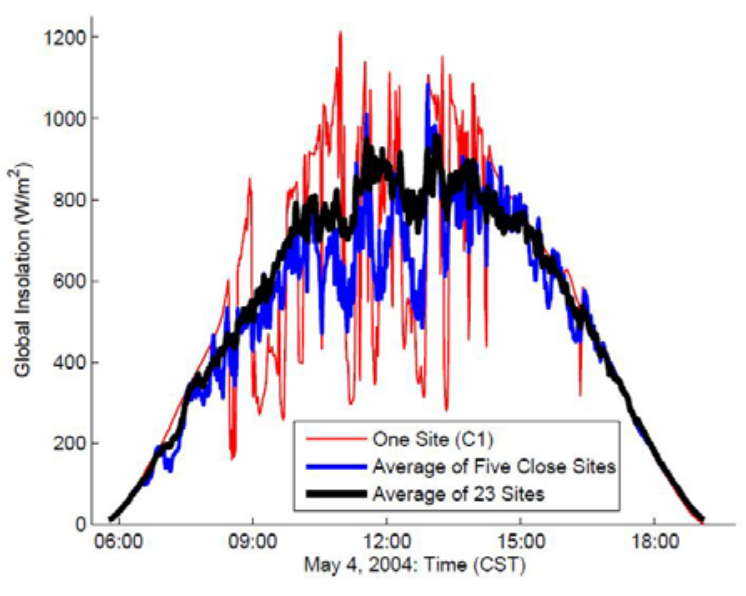

Figure 2. Example of 1-min global insolation on a partly cloudy day from one site, the average of five close sites, and the average of 23 sites

(Source: Mills and Wiser 2010)
A rooftop solar installation provides a useful illustration of variability: transient events such as cloud passage can reduce output quite rapidly (see Figure 2).

Figure 2 also illustrates how spreading solar photovoltaics (PV) over a larger geographic area tends to reduce aggregate variability.

Generally, solar PV output is more variable than wind (changing faster on a minute-tominute basis), but it is less uncertain. With both wind and solar power, the ability of system and generation operators to predict generation levels is improving (Bullis 2014).

\section{Balancing supply and demand during generation scarcity and surplus situations}

Related to but distinct from the previous challenge is system operators' need to balance supply and demand in situations of high RE production and low demand or low RE production and high demand. Supply of wind and solar may not coincide closely with demand, introducing challenges at the bulk power system level and - if there is significant distributed PV generation - at the local distribution system level. An illustration of the distribution system

\footnotetext{
${ }^{1}$ It should be noted that greater geographic diversity of wind and solar plants tends to have a smoothing effect, reducing overall uncertainty and variability.
} 
challenge is 'reverse power flow' that can occur during the middle of the day from areas with large amounts of distributed PV. When most people are out of their homes at work, residential electricity demand is low, so more of the generated electricity feeds back up through the transformer to the medium-voltage network. Distribution systems have not traditionally needed to anticipate this situation because most generation has come from large-scale systems located on the transmission grid, with power flowing predictably one way down to lower voltage systems.

Nighttime wind provides an illustration of the supply-demand challenge on the bulk power system. When nighttime demand is very low and wind is strong (for example on a windy springtime night), there may be insufficient demand to utilize all of the wind power, and conventional generators may not be able or willing to reduce their generation further to make space for the wind power. In this case, insufficient power system flexibility could result in 'curtailed' wind power.

Challenges related to high peak load during periods of low variable RE production are less technically demanding and are primarily economic challenges related to market solutions chosen to remunerate reserve capacity or demand response activities.

\section{Smart grid solutions emerging to manage continuous balancing of the system include:}

- Better forecasting. Widespread instrumentation and advanced computer models allow system operators to better predict and manage RE variability and uncertainty.

- Smart inverters. Inverters and other power electronics can provide control to system operators, as well as to automatically provide some level of grid support.

- Demand response. Smart meters, coupled with intelligent appliances and even industrialscale loads, can allow demand-side contributions to balancing.

- Integrated storage. Storage can help to smooth short-term variations in RE output, as well as to manage mismatches in supply and demand.

- Real-time system awareness and management. Instrumentation and control equipment across transmission and distributions networks allows system operators to have real-time awareness of system conditions, and increasingly, the ability to actively manage grid behavior.

\subsection{Economic, Policy, and Regulatory Challenges}

In addition to technical challenges, institutional challenges also arise with increasing shares of variable RE. Broadly these relate to the unique economics of variable $R E$, which give rise to various policy and regulatory issues. Two specific challenges are identified here: capitalintensive grid upgrades, and uncertain project costs and cash flows.

\section{Capital-intensive grid upgrades}

Grid upgrades may be required to accommodate wind and solar power. For example, to the extent high quality wind and solar resources are located far from demand centers, new transmission lines or upgrades to existing lines may be required. At the distribution level, rooftop PV may accelerate the fatigue of distribution components, such as low-voltage transformers, 
moving forward the need for grid upgrades. Minimizing the cost of upgrades, while ensuring system reliability, translates to greater value from RE investments.

\section{Uncertain RE project costs and cash flows}

Smart grid solutions are emerging to two specific issues that historically have negatively impacted RE project economics: grid upgrade costs allocated to RE project developers, and energy curtailment when full RE production cannot be readily integrated into the power system. Both issues may cause cash flows of the project to diverge further from expectation. ${ }^{2}$ To the extent upgrades become costly or curtailments increase, the investment landscape for variable $\mathrm{RE}$ becomes more uncertain and can slow overall deployment.

In cases where policy measures and subsidies insulate project investors from these risks-for example to further enhance the investment environment for RE - costs and risks may be socialized. Smart grid investments can also play an important role in reducing those costs and risks.

Cost-effective methods of reducing curtailment and minimizing new transmission or grid upgrades can therefore capture more value from RE sources, improve the viability of individual RE projects, and maximize value to the system, enhancing the overall investment climate.

\section{Smart grid solutions emerging to address the economic, policy, and regulatory challenges of variable $R E$ include:}

- Dynamic line rating. Real-time information about transmission line capacity can allow grid operators to extract more value from existing lines, reducing the need for costly upgrades.

- Demand response. Enabled by smart meters and intelligent loads, customer demand response solutions can help absorb excess RE generation, reducing the need for distribution upgrades.

- Smart inverters and other advanced power controls. Smart inverters and other power controls can reduce the need for significant grid transmission and distribution upgrades, thus reducing costs that may otherwise be levied on RE projects or socialized.

- Grid-scale storage. Large-scale storage of various types can help to reduce the need for additional transmission capacity.

- Behind-the-meter storage. Customer storage solutions can help absorb excess PV generation, reducing the need for distribution upgrades.

- Advanced energy management systems. Advanced energy management systems that provide real-time, high-resolution visibility and control of power systems, can allow grid operators to defer more costly capital expenditures.

- Better forecasting. System-level forecasting can help system operators operate their grids more flexibly, allowing more production to be accepted.

\footnotetext{
${ }^{2}$ This problem is most relevant for projects whose cash flows depend directly on delivered energy. In contrast, some jurisdictions require that the grid operator compensate project owners for curtailed energy, thus spreading risk more broadly and providing an incentive for the grid operator to integrate as much delivered energy as possible.
} 


\section{International Case Studies: Who is Active in This Area?}

The following case studies from Sweden, the Republic of Korea, Austria, the United States, and Canada highlight a selection of the smart grid technologies and practices that can be deployed to better support the technical and economic integration of variable RE. Specifically, the cases explore dynamic line ratings, energy storage and system management, voltage controls, regulations and smart inverters, and system awareness (i.e., visualization). This selection is not comprehensive. Other examples exist, and this list is presented in the hope that it will spur the addition of more examples over time.

\subsection{Sweden: Gotland Wind Farm and Dynamic Line Rating}

The 48-MW Kårehamn wind farm on the island of Öland in Sweden offers an example of how one power company was able to use dynamic line ratings ${ }^{3}$ to increase line capacity by $60 \%$, closer to true operational limits. Over the past six to seven years, Öland island has seen significant additions of grid-connected wind power. A static line rating was used to determine that new transmission line investments would have been needed to accommodate power from the planned Kårehamn wind farm. The transmission line investments would have cost an estimated US\$9 million to 16 million (approximately 60 to 100 million Swedish Krona [SEK]). Utilizing dynamic line rating, in contrast, was estimated to cost less than one-tenth of the original estimate (approximately US\$750,000 or 5 million SEK). The dynamic line rating option was thus chosen for trial implementation (Swedish Coordination Council for Smart Grid 2014).

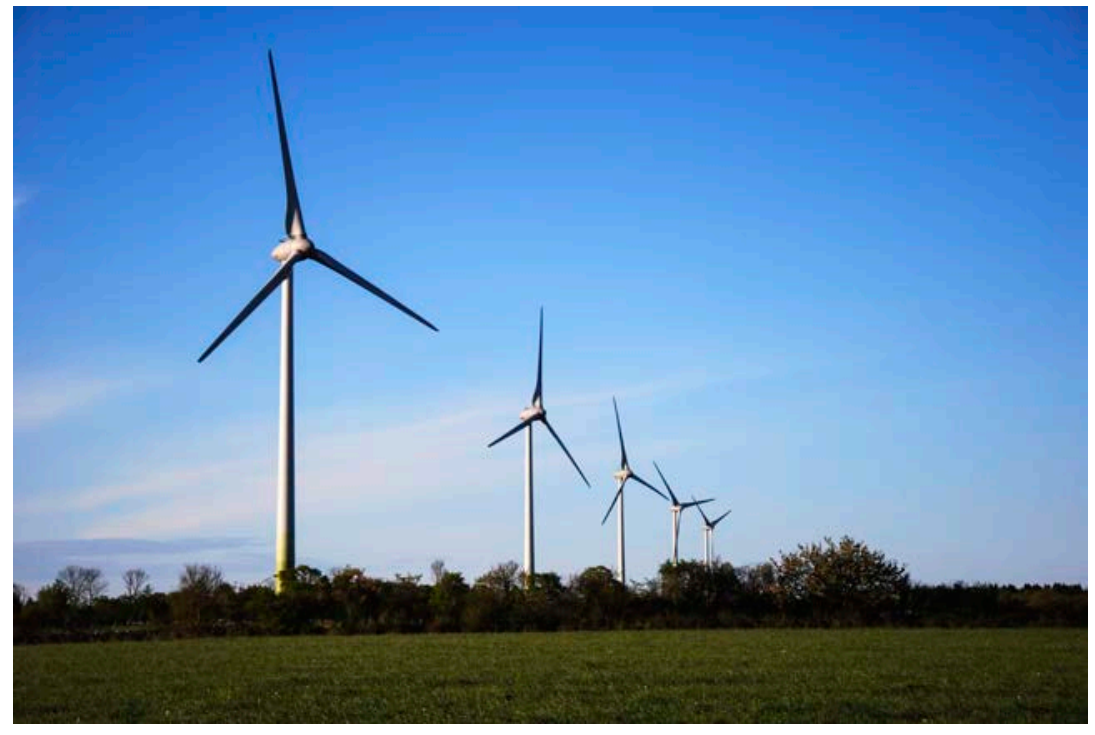

Figure 3. The Island of Öland

Source: iStock 53580438

\footnotetext{
${ }^{3}$ A dynamic line rating can be achieved through real-time determination of an element's ability to carry load based on electrical and environmental conditions (definition adapted from ISGAN).
} 
Initially, the transmission line serving the wind farm was estimated to handle up to $30 \mathrm{MW}$ of additional power. Using frequently updated measurements and monitoring of the line's temperature, power transfer, and ambient air temperature has enabled the line capacity to be increased to $48 \mathrm{MW}$. In the event the line is overloaded, the Kårehamn wind farm receives a message to curtail its power output.

Improper use of dynamic line ratings might, however, increase the risk for line failure and may also increase line losses due to the higher line temperature. Operating the line with higher rates of losses could negatively impact the revenue cap for the grid company that is set by regulators, who may allow a higher rate for grid companies with few interruptions in delivery and low network losses. Also, the grid company currently cannot share the cost savings of using dynamic line rating with the customer, i.e., the wind generator. However, given the significant cost savings, the utility E.ON suggests further roll-out of dynamic line ratings and exploration of regulatory incentives to improve savings allocation to the customer (personal communications with E.ON).

\subsection{Korea: Gapa Island Smart Grid Energy Self-Sufficiency Model}

Korea provides an interesting example in its development of the Gapa island as an energy selfsufficiency model for smart grid and renewable energy deployment. The island has been building off of the experience of the nearby Jeju provincial island, also known for its advanced work on smart grids and the Carbon Free Island by 2030 project.

Gapa is an island of $8.5 \mathrm{~km}^{2}$ and had a resident population of 281 in 2012. Wind and solar PV generation systems of $500 \mathrm{~kW}$ and $111 \mathrm{~kW}$, respectively were installed on Gapa to replace a $450-\mathrm{kW}$ diesel generator. The renewable electricity generation systems have been complemented with a 1-MW Lithium-ion battery, a power conditioning system, and an advanced energy management system to help manage RE variability and uncertainty. The storage system serves to not only support flexibility of the grid system but also to provide initial start-up power to the wind turbine. In addition, the automated power management system, which tracks electricity on a real-time basis, helps to optimize grid operation. This project is further described in Figure 4 below. 


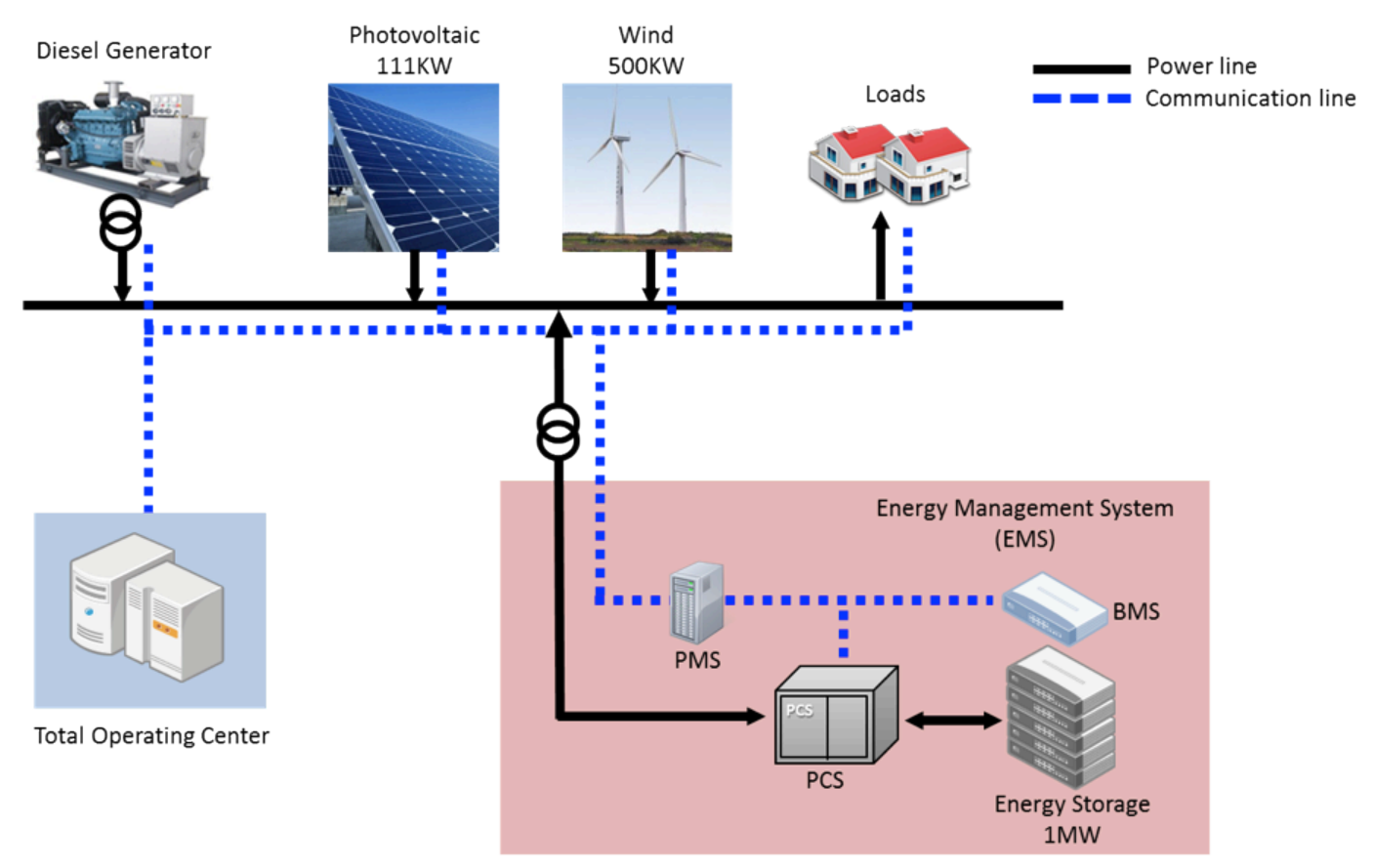

Figure 4. Schematic illustration of the Gapa Island Smart Grid Model, Korea

Source: Internal KSGI Document

The combination of energy storage, advanced energy management, and renewables has made Gapa a carbon free electricity system. The benefits of the project are an estimated US $\$ 415,000$ (450 million Korean Won) through avoided fuel costs and reductions of more than 750 tons of $\mathrm{CO}_{2}$ emissions, annually. ${ }^{4}$ Based on this proven model, which generates electricity from renewables and storage and power system management technologies, Korea plans to roll-out the self-sufficient grid concept on other small islands that have traditionally depended on instable fossil fuel supplies.

\subsection{Austria: Smart Grid Pilots in the Salzburg Region}

Pilot projects in the Salzburg region of Austria are being undertaken to test, inter alia, voltage control on distribution networks. ${ }^{5}$ One pilot in the town of Lungau, a rural town with significant potential for hydro, wind, and solar power, deployed an advanced energy management system that resulted in a $20 \%$ increase in distribution network capacity on the $30-\mathrm{kW}$ lines. This increase in network capacity, and the ability to more accurately control voltage, has allowed more RE to be deployed while deferring the need for more costly upgrades. It is estimated this pilot approach could save approximately 2,200,000 liters of crude oil as a primary source of energy and to reduce $\mathrm{CO}_{2}$ emission by 5,500 tons per year (Grid Innovation Online n.d.).

\footnotetext{
${ }^{4}$ The estimation is based on offsetting 1,045 MWh per year of electricity generated from diesel.

${ }^{5}$ Austria is also testing voltage controls in low voltage network with the DG Demo Net Mart Low Voltage Grid in Köstendorf. However, application of voltage controls in low voltage networks is more challenging than that in medium voltage networks given the large number of producers and consumers.
} 
Another pilot was demonstrated at the Turrach hydropower plant, which was initially determined to need a $14 \mathrm{~km}$-long cable to supply its power to the grid. With implementation of voltage controls, the length of the line was reduced to $50 \mathrm{~m}$, providing significant cost savings of US $\$ 2.3$ million ( $€ 1.67$ million) compared with US\$27,000-\$69,000 (€30,000-€50,000) adaptation and connection costs. Additional benefits include improved security of supply, increased share of renewable energy, and reduced emissions (Kupzog et al. 2013).

\subsection{California Rule 21 on Smart Inverters}

The California Public Utilities Commission (CPUC) is advancing the deployment of smart inverters on distributed PV systems to reduce system impacts of growing PV deployment. CPUC Rule 21 defines the state's interconnection, operating, and metering requirements for generators connected to the distribution grid. Rule 21 was updated in July 2014 to enable interconnection of smart inverters. Smart inverters can provide volt-VAR control, voltage and frequency event ridethrough, grid monitoring, high-frequency power reduction, and ramp-rate control (IRENA 2013; Ormond 2014). These benefits are expected to allow for higher deployment of PV while reducing system impacts and the potential need for grid upgrades.

California is the first U.S. state to allow for advanced inverters, following in the footsteps of several countries in Europe (Clover 2015). Previously, some inverters were being sold in the United States with smart functionalities that were "turned off" because they were not allowed.

The rule is based on the policies developed by the Smart Inverter Working Group, a collaboration between the CPUC and California Energy Commission (CEC) staff along with the Institute of Electric and Electronics Engineers (IEEE), and other standards organizations and stakeholders. ${ }^{6}$ The rule does not apply to existing inverters or back-up power systems (Clover 2015). However, inverters typically need to be replaced every 7 to 9 years over a 20+ year lifespan for a PV system (Ormond 2014). Thus, current inverters with smart functionalities can be turned on and new smart inverters are likely to be installed in the near future as older inverters are replaced and new systems built.

\subsection{Ontario, Canada: "SmartMap" Distribution System Geographic Analysis Tool}

Ontario, through its Smart Grid Fund (SGF) program, is supporting the demonstration and commercialization of enabling technologies that allow for better distribution network planning and more reliable system operation with growing proportions of variable RE.

One key example is Essex Energy Corporation's (EEC) SmartMap distribution monitoring and control system. SmartMap provides utilities with a geographic analysis tool for medium-voltage distribution systems, taking data from smart meters, wholesale meter points, and other sensors to create a sophisticated distribution system simulation. The platform then uses real, measured voltage and load meter data to provide a realistic portrait of the distribution system from the transmission substation all the way down to individual meters. The geographic user interface

\footnotetext{
${ }^{6}$ The Smart Inverter Working Group's efforts are being informed, in part, by international work on smart inverter test protocols led by Sandia National Laboratories (U.S.) under ISGAN Annex 5: Smart Grid International Research Facility Network (SIRFN).
} 
allows utility operators to view important information about any individual feeder line, including real and reactive power, percentage loading, current, and losses. With this vital information, utilities are better able to plan for, and operate, a grid with growing distributed generation. Other expected benefits include faster outage restoration and automated customer alerts.

With the support of SGF, EEC and its data management partner, Utilismart, developed and integrated SmartMap into Essex Powerlines' operations from 2012 through 2014. Through continuous testing and refinement, SmartMap collects, reports, and allows action on key renewable integration requirements such as:

- Use of 5-minute and 1-hour interval data to identify minimum, maximum, and median system conditions

- Identification of loading capacity and fault current capacity down to the individual feeder

- Accurate simulation of proposed future system states

- Monitoring of secondary voltage levels on all transformers in 15 minutes increments

- Automatic response to generator dispatch requests from the province-wide system operator.

Figure 5 demonstrates what utility operators see when using SmartMap to view specific feeder performance. Through using SmartMap, Essex Powerlines has been able to safely integrate 14 renewable energy projects, representing $550 \mathrm{~kW}$ of capacity, with complete visibility into the performance of resources as small as $10 \mathrm{~kW}$ or less.

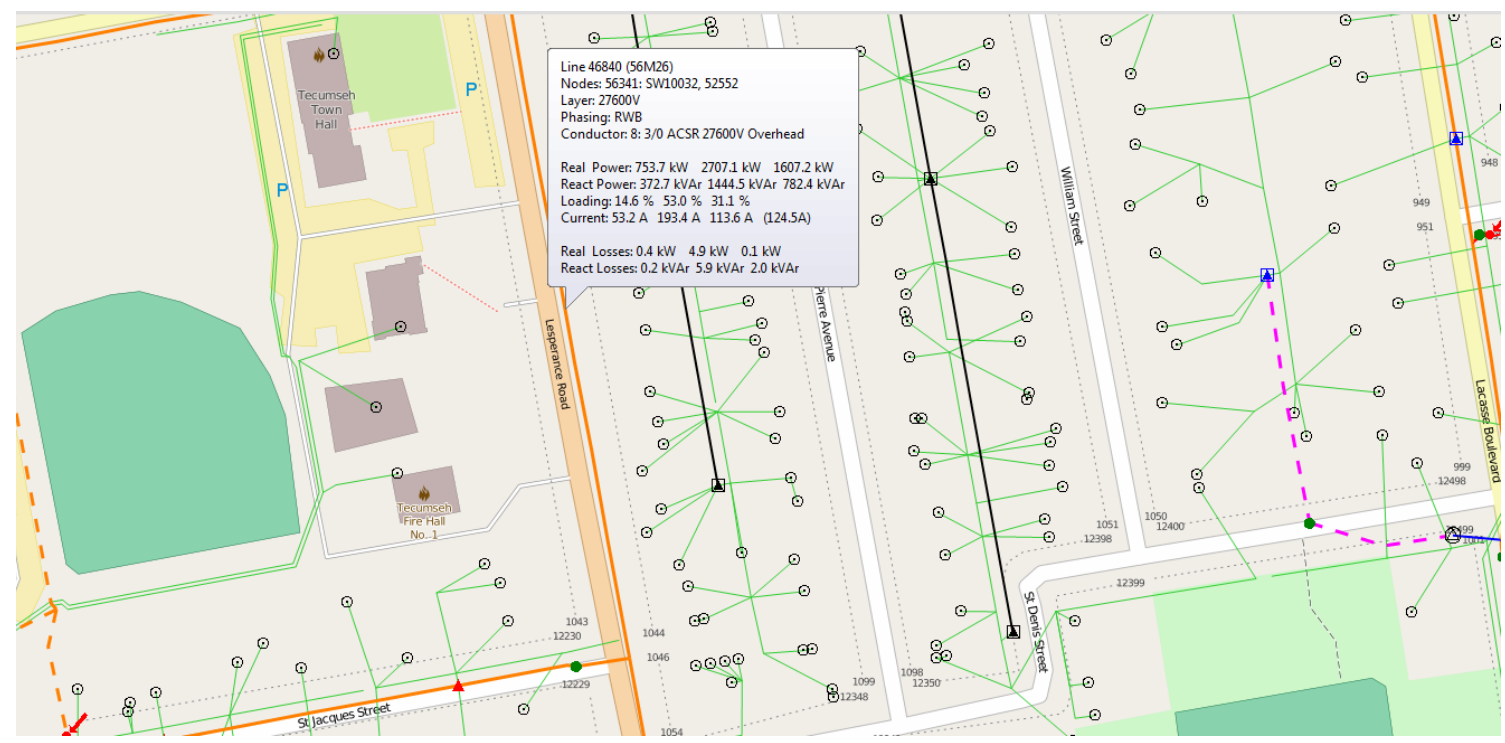

Figure 5. SmartMap's Load Flow Analysis calculates system loading, which is used to determine remaining capacity on a feeder.

\footnotetext{
${ }^{7}$ For more information on this project, visit http://www.energy.gov.on.ca/en/smart-grid-fund/smart-grid-fundprojects/essex-energy-corp/and http://www.utilismartcorp.com/?page id=1868.
} 


\section{Conclusion: Trends to Watch in 2015 and Beyond}

System operators and energy planners must overcome several challenges when integrating high penetrations of variable RE. These challenges can be roughly grouped as either technical or economic, policy, and regulatory in nature. Solutions to four specific challenges are emerging, and will be important to watch in coming years:

- Technical: Managing variability and uncertainty during the continuous balancing of the system

- Technical: Balancing supply and demand during generation scarcity and surplus situations

- Economic, Policy, and Regulatory: Deferring or avoiding capital-intensive grid upgrades

- Economic, Policy, and Regulatory: Enhancing RE project returns to enhance the investment environment.

Fortunately, there already exist a variety of potential technology and practical solutions that can be used to overcome these challenges, such as improved forecasting, smart inverters, demand response, storage (distributed and large-scale), real-time system awareness, and dynamic line rating. New advanced energy management protocols in the transmission and distribution operator interfaces can also support flexible integration of variable RE.

As demonstrated by the case studies examined within this report, smart grid technologies can enhance flexible operation of the grid, improve utilization of existing infrastructure, improve cost effectiveness of grid operations, and defray large-scale investments. Through these mechanisms, smart grid technologies help systems operators and policy makers to affordably attain renewable energy deployment goals, lower greenhouse gas emissions, and ensure reliable system operation.

In order to improve the speed and effectiveness of a transition towards a smarter grid that enables integration of higher shares of renewables, regulators and policy makers will need to bring together the domains of technologies, operational practices, and institutional arrangements. Effective power system policy and regulation will increasingly operate at this crucial intersection. In support of effective policy and regulation, ISGAN and its institutional partners will continue to collect and track the impacts of smart grid projects, share knowledge among practitioners and decision makers, and produce targeted analysis on key topics. 


\section{References}

Bullis, K. 2014. "Smart Wind and Solar Power." MIT Technology Review. Accessed May 2015, http://www.technologyreview.com/featuredstory/526541/smart-wind-and-solar-power/.

California Independent System Operator (CAISO). "Briefing on the CAISO Renewable Integration Study." October 17, 2007.

California Public Utilities Commission (CPUC). "Rule 21." Last Modified March 19, 2015. http://www.cpuc.ca.gov/PUC/energy/rule21.htm.

Clover, Ian. 2015. "California adopts pioneering advanced inverter standards." PV Magazine, January 8. Accessed April 2015, http://www.pv-magazine.com/news/details/beitrag/californiaadopts-pioneering-advanced-inverter-standards_100017709/\#axzz3ZTA3QFHL.

Grid Innovation Online. "SGMS- The integration of renewables in distribution networks." Undated. Accessed May 2015, http://www.gridinnovation-on-line.eu/Articles/Library/SGMS-The-Integration-Of-Renewables-In-Distribution-Networks.kl\#sthash.7lfjnp6i.dpuf.

International Renewable Energy Agency (IRENA) (2013). "Smart Grids and Renewables: A Guide for Effective Deployment." Accessed May 19, 2015, https://www.irena.org/DocumentDownloads/Publications/smart_grids.pdf.

International Smart Grid Action Network (ISGAN). ISGAN Smart Grid Glossary. Accessed May 20, 2015: http://en.openei.org/wiki/ISGAN_Smart_Grid_Glossary.

Kupzog, Friederich, Helfried Brunner, Johann Schrammel, Susen Döbelt, Alfred Einfalt, Andreas Lugmaier, Mike Pichler, Daniel Reiter, Hans Jürgen Bacher, Laura Emmermacher, Marietta Stutz, Markus Berger, Thomas Rieder, Herwig Struber, Bernhard Kaiser, Georg Kienesberger, and Wolfgang Prüggler. 2013. Results \& Findings from the Smart Grids Model Region Salzburg. Salzburg, Austria: Salzburg AG. Accessed May 4, 2015, http://www.smartgridssalzburg.at/fileadmin/user_upload/downloads/SGMS_Results_Findings 0 5-2013.pdf.

Mills, Andrew, and Ryan Wiser. 2010. Implications of Wide-Area Geographic Diversity for Short-Term Variability of Solar Power. LBNL-3884E._Berkeley, CA: Lawrence Berkeley National Laboratory. Accessed May 2015, http://emp.lbl.gov/sites/all/files/REPORT\%20lbnl3884e.pdf.

Ormond, Jamie. 2014. "California's Interconnection Rule 21 and Smart Inverter \& Smart Inverter Working Group." Presentation to the New England Independent System Operator, July 11, 2014. Accessed May 2015, http://www.isone.com/committees/comm wkgrps/prtcpnts comm/pac/mtrls/2014/jul112014/california smart i nverter working group.pdf.

Swedish Coordination Council for Smart Grid. "Samordningsrådet för smarta elnät, Planera för effekt!, SOU 2014:84, Chapter 5.4.1, Page 256. 2014.

Widegren, Karin, Energimarknadsinspektionen. Personal communications with E.ON, MarchMay 2015. 